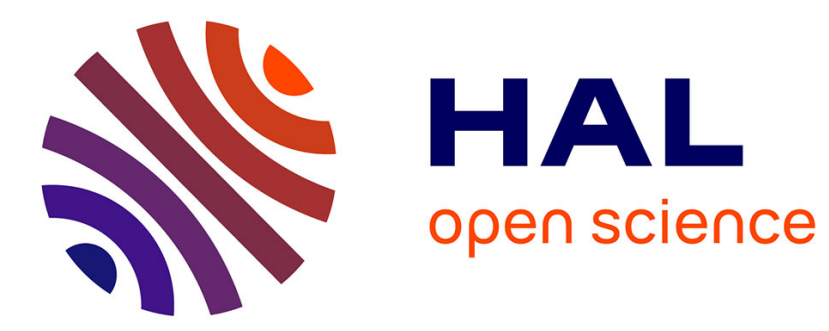

\title{
An Adaptive Electric Differential for Electric Vehicles Motion Stabilization
}

\author{
Bekheira Tabbache, Abdelaziz Kheloui, Mohamed Benbouzid
}

\section{To cite this version:}

Bekheira Tabbache, Abdelaziz Kheloui, Mohamed Benbouzid. An Adaptive Electric Differential for Electric Vehicles Motion Stabilization. IEEE Transactions on Vehicular Technology, 2011, 60 (1), pp.104-110. 10.1109/TVT.2010.2090949 . hal-00564728

\section{HAL Id: hal-00564728 \\ https://hal.science/hal-00564728}

Submitted on 9 Feb 2011

HAL is a multi-disciplinary open access archive for the deposit and dissemination of scientific research documents, whether they are published or not. The documents may come from teaching and research institutions in France or abroad, or from public or private research centers.
L'archive ouverte pluridisciplinaire HAL, est destinée au dépôt et à la diffusion de documents scientifiques de niveau recherche, publiés ou non, émanant des établissements d'enseignement et de recherche français ou étrangers, des laboratoires publics ou privés. 


\title{
An Adaptive Electric Differential for Electric Vehicles Motion Stabilization
}

\author{
Bekheira Tabbache, Abdelaziz Kheloui, and Mohamed El Hachemi Benbouzid, Senior Member, IEEE
}

\begin{abstract}
This paper proposes a traction drive system for electric vehicles (EVs) with two separate induction motor drive-based wheels. In this case, an electric differential (ED) is developed. To handle EV stability while cornering or under slippery road condition, the proposed traction drive uses direct torque control and an adaptive-flux-and-speed-observer-based algorithm. EV-specific experimental tests on a digital signal processor TMS320LF2407 are carried out to show the effectiveness of the proposed adaptive ED in terms of robustness and stability.
\end{abstract}

Index Terms-Adaptive observer, direct torque control (DTC), electric differential (ED), electric vehicle (EV).

\section{NOMENCLATURE}

$s,(r)$ Stator (rotor) index.

$\alpha, \beta \quad$ Synchronous reference frame index.

$l, r \quad$ Left and right motor subscripts.

$\wedge \quad$ Estimated quantity.

* $\quad$ Reference quantity.

$V(i) \quad$ Voltage (Current).

$\varphi \quad$ Flux.

$\omega_{r} \quad$ Rotor electric speed.

$T$ Motor torque.

$R \quad$ Resistance.

$L \quad$ Inductance.

$L_{m} \quad$ Magnetizing inductance.

$\sigma \quad$ Leakage coefficient $\sigma=1-L_{m}^{2} / L_{s} L_{r}$.

$T_{r} \quad$ Rotor time constant $\left(T_{r}=L_{r} / R_{r}\right)$.

$T_{s} \quad$ Stator time constant $\left(T_{s}=L_{s} / R_{s}\right)$.

$p \quad$ Pole-pair number.

$v \quad$ Vehicle speed.

$r \quad$ Vehicle wheel radius.

$\Omega \quad$ Motor speed.

\section{INTRODUCTION}

G ENERALLY, in most electric vehicle (EV) propulsion applications, an ac motor is connected to the wheels by reduction gears and a mechanical differential. In some vehicle drive arrangements, high-speed, low-torque wheel motors

Manuscript received July 13, 2010; revised September 23, 2010; accepted October 25, 2010. Date of publication November 9, 2010; date of current version January 20, 2011. The review of this paper was coordinated by Dr. A. Khaligh.

B. Tabbache is with the University of Brest, 29238 Brest, France, and also with the Department of Electrical Engineering, Polytechnic Military Academy, 16111 Algiers, Algeria.

A. Kheloui is with the Department of Electrical Engineering, Polytechnic Military Academy, 16111 Algiers, Algeria.

M. E. H. Benbouzid is with the University of Brest, 29238 Brest, France (e-mail: Mohamed.Benbouzid@univ-brest.fr).

Color versions of one or more of the figures in this paper are available online at http://ieeexplore.ieee.org.

Digital Object Identifier 10.1109/TVT.2010.2090949

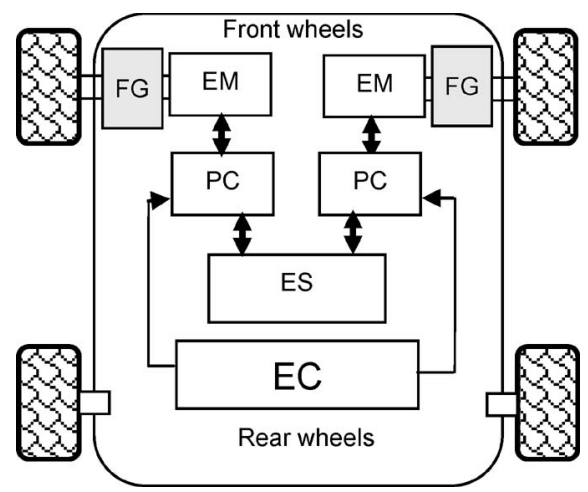

Fig. 1. EV dual-motor configuration (FG: fixed gear, EM: electrical motor, EC: electronic controller, ES: energy source, PC: power converter).

requiring gear reduction are used, and in these cases, either a gear motor assembly is mounted inside the wheel, or a chassismounted motor is connected to the wheel through gear reduction. Further simplification of the vehicle drive arrangement results in the elimination of the gear being interposed between motor and wheel. The above then calls for the use of an electric differential (ED) [1]-[4].

ED-based EVs have advantages over classical EVs with a central motor. Indeed, mounting the motors directly to the wheels simplifies the mechanical layout. The ED system will reduce the drive line components, thus improving the overall reliability and efficiency. This option will also reduce the drive line weight since mechanical differential and gear reduction are not used. However, one of the main issues in the design of these EVs (without mechanical differential) is to ensure vehicle stability in particular while cornering or under slippery road conditions [2]. This calls for a specific traction control system [5].

In this context, the induction motor has been adopted as the EV propulsion base [6]. Among the available induction motor control techniques, direct torque control (DTC) appears to be very convenient for EV applications [5], [7], [8]. DTC has the advantage of not requiring speed or position encoders and uses voltage and current measurements only. Flux, torque, and speed are estimated. It also has a faster dynamic response due to the absence of a proportional-integral (PI) current controller. The input of the motor controller is the reference speed, which is directly applied by the pedal of the vehicle. However, typical advantages of DTC are not sufficient in particular regarding low-speed operation and parameter variations. This calls then for the use of adaptive observers. In this case, the Luenberger observer is adopted for the flux and speed estimation [9]-[11].

Specific experimental tests on a digital signal processor (DSP) TMS320LF2407 are carried out to demonstrate the feasibility and the effectiveness of the proposed adaptive ED in terms of robustness and stability. 


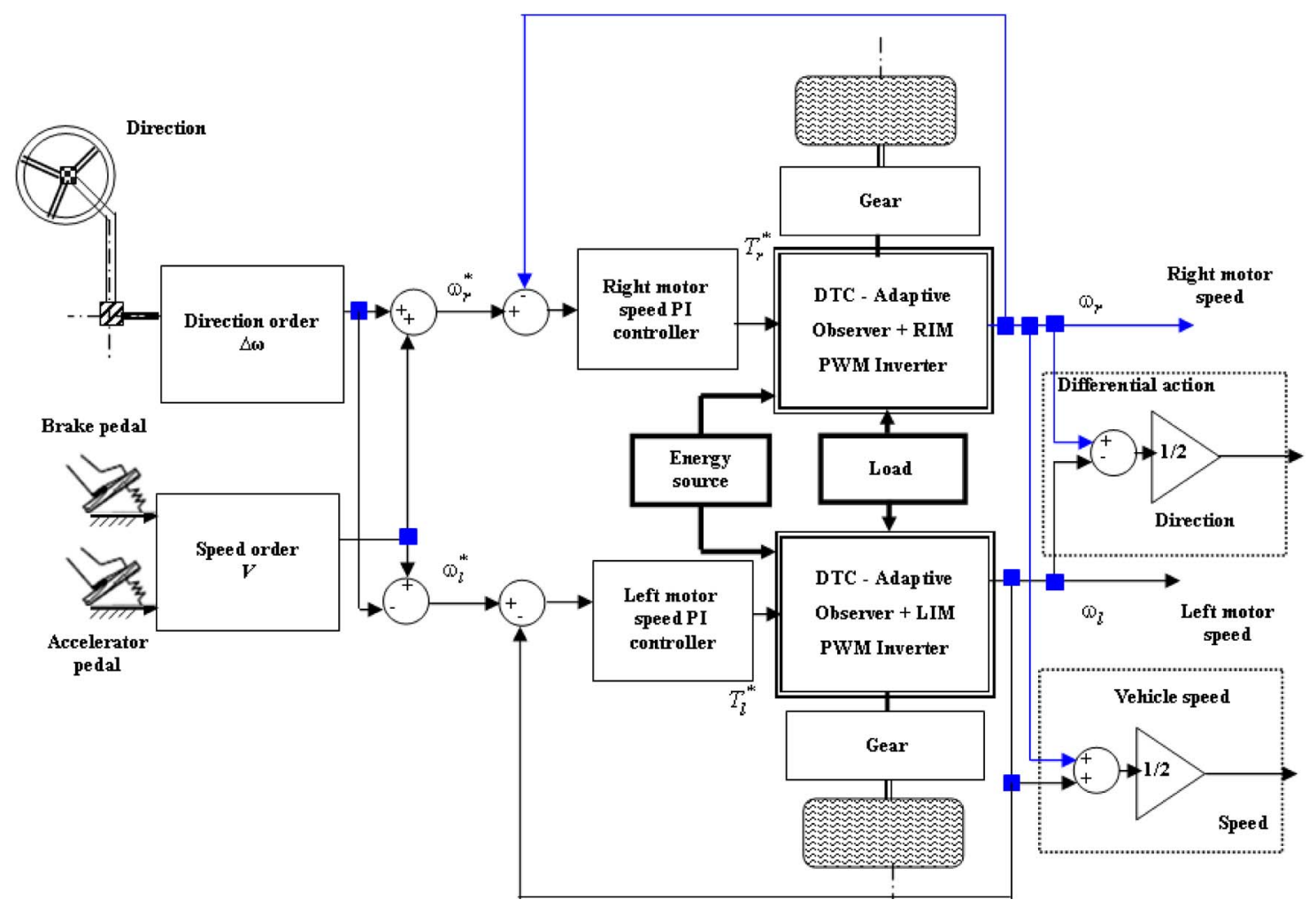

Fig. 2. Proposed EV propulsion and control system schematic diagram.

\section{Electric Vehicle Dual-Motor Configuration}

There are several possible EV configurations regarding the electric propulsion and the energy sources [12]. In the adopted dual-motor configuration, the ED is associated with front wheels and has specific features over [1] (see Fig. 1).

\section{Control of the Electric Differential-BASED Electric Vehicle Traction Drive}

The proposed ED-based EV dual-motor traction drive is shown in Fig. 2. In this configuration, the EV wheels are coupled to the induction motors via fixed gears. The left and right induction motors are fed by two power inverters and controlled by a DTC strategy. The speeds used by the right and left motor speed controllers are estimated using adaptive observers. In a turning way, the quantity provided by the steering wheel is added to the vehicle reference speed for the external wheel and extracted from the vehicle reference speed for the internal wheel. This will generate the left and right induction motor reference speeds. The DTC torque references are obtained using PI controllers.

\section{A. Direct Torque Control}

DTC is an alternative method to flux-oriented control. The basic principle is the selection of the electromagnetic torque and stator flux references by choosing the appropriate inverter state. Several advantages may be considered: nearly sinusoidal stator flux and current waveforms; higher robustness regarding motor parameter variations, except the stator winding resistance; higher torque dynamics; and easier flux and speed estimator implementation since coordinate transformation is not required [7], [8].

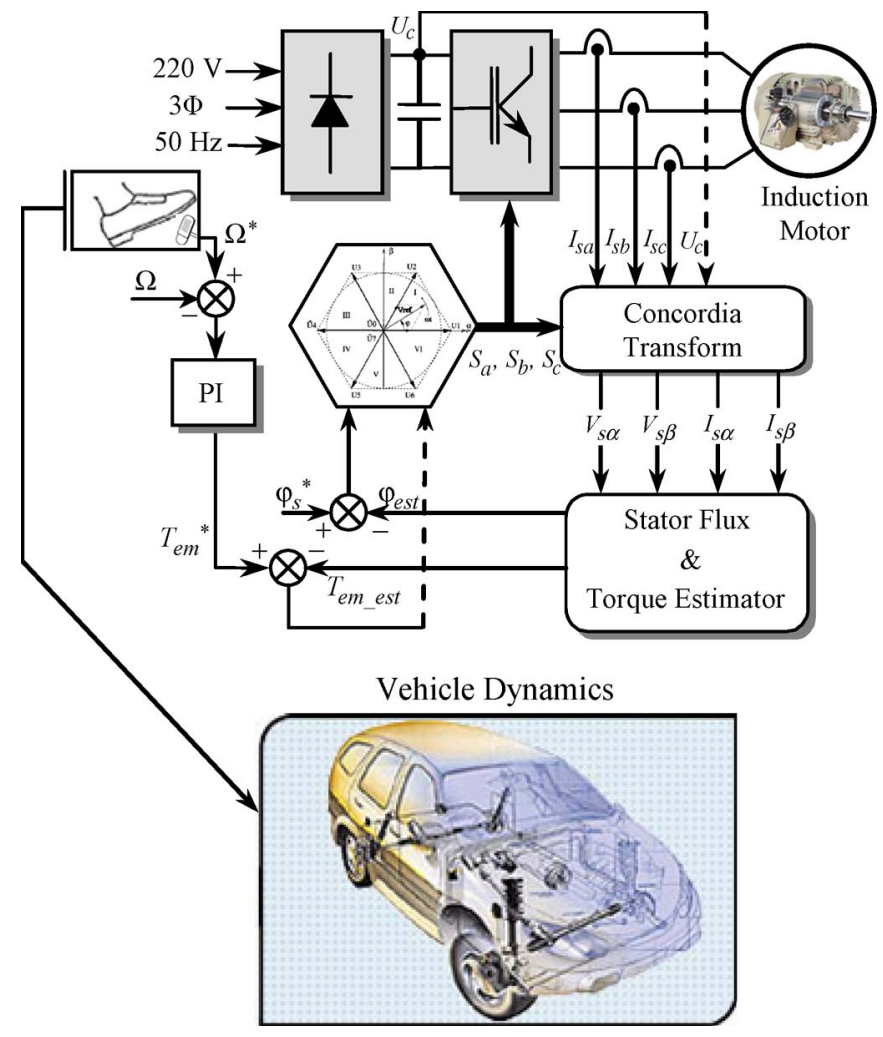

Fig. 3. DTC block diagram.

A DTC conventional type is used as shown in Fig. 3 [7]. It includes hysteresis regulators and a commutation table. The reference torque $\left(T_{e m}^{*}\right)$ is given by the speed controller, which is of PI type. 


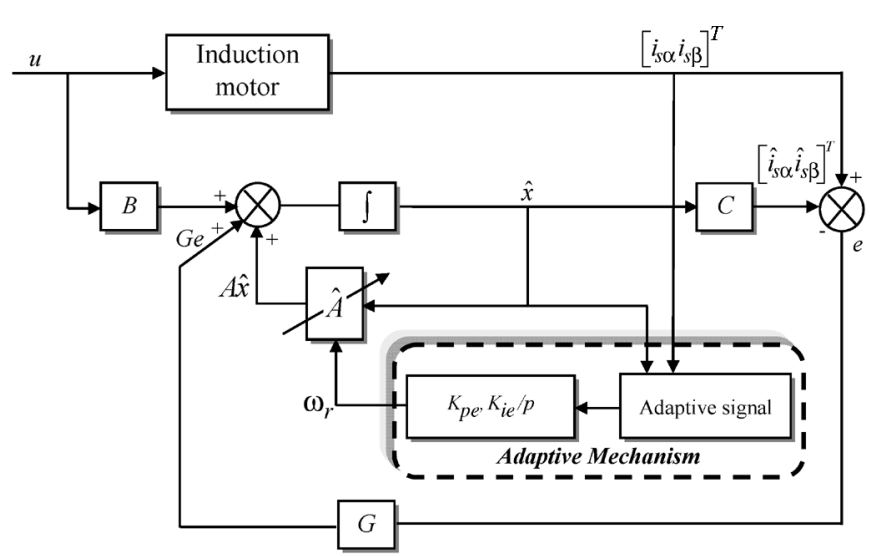

Fig. 4. Adaptive observer global structure.

As DTC implementation requires torque and flux knowledge, a more elaborate and efficient solution for that purpose consists of using state observer determinist types such as the Luenberger observer [9]-[11]. In this case, the flux components are obtained using an adaptive observer that is also used to estimate the two induction motor speeds [13]. The estimated torque is given by

$$
\hat{T}_{e m}=\frac{3}{2} p\left(\hat{\varphi}_{s \alpha} i_{s \beta}-\hat{\varphi}_{s \beta} i_{s \alpha}\right)
$$

\section{B. Flux and Speed Observer}

In this paper, an adaptive flux and speed observer is adopted. This observer uses the observed system model. It calculates the stator flux and rotational speed estimated values using the motor drive measurements (stator currents and dc voltage).

The induction motor state model developed in the stationary reference frame is given as follows [13]:

$$
\left\{\begin{array}{l}
\frac{d x}{d t}=A x+B u \\
y=C x
\end{array}\right.
$$

where $x=\left[\begin{array}{llll}i_{s \alpha} & i_{s \beta} & \varphi_{r \alpha} & \varphi_{r \beta}\end{array}\right]^{\mathrm{T}}$ is the state vector, $u=$ $\left[\begin{array}{ll}V_{s \alpha} & V_{s \beta}\end{array}\right]^{\mathrm{T}}$ is the input vector, and $y=\left[\begin{array}{ll}i_{s \alpha} & i_{s \beta}\end{array}\right]^{\mathrm{T}}$ is the output vector, with

$A=\left[\begin{array}{cccc}-\frac{1}{\sigma}\left(\frac{1-\sigma}{T_{r}}+\frac{1}{T_{s}}\right) & 0 & \frac{L_{m}}{\sigma L_{s} L_{r} T_{r}} & \frac{L_{m}}{\sigma L_{s} L_{r}} \omega_{r} \\ 0 & -\frac{1}{\sigma}\left(\frac{1-\sigma}{T_{r}}+\frac{1}{T_{s}}\right) & -\frac{L_{m}}{\sigma L_{s} L_{r}} \omega_{r} & \frac{L_{m}}{\sigma L_{s} L_{r} T_{r}} \\ \frac{L_{m}}{T_{r}} & 0 & -\frac{1}{T_{r}} & -\omega_{r} \\ 0 & \frac{L_{m}}{T_{r}} & \omega_{r} & -\frac{1}{T_{r}}\end{array}\right]$
$B=\left[\begin{array}{cc}\frac{1}{\sigma L_{s}} & 0 \\ 0 & \frac{1}{\sigma L_{s}} \\ 0 & 0 \\ 0 & 0\end{array}\right] \quad C=\left[\begin{array}{llll}1 & 0 & 0 & 0 \\ 0 & 1 & 0 & 0\end{array}\right]$.

The estimated speed $\omega_{r}$ is considered as a variable parameter. Using (2), a global observer structure can be written as

$$
\frac{d \hat{x}}{d t}=\hat{A} \hat{x}+B u+G(y-\hat{y})
$$

where $G$ is the observer gain matrix, which is selected to ensure system stability. The global adaptive flux and speed observer structure is shown in Fig. 4.

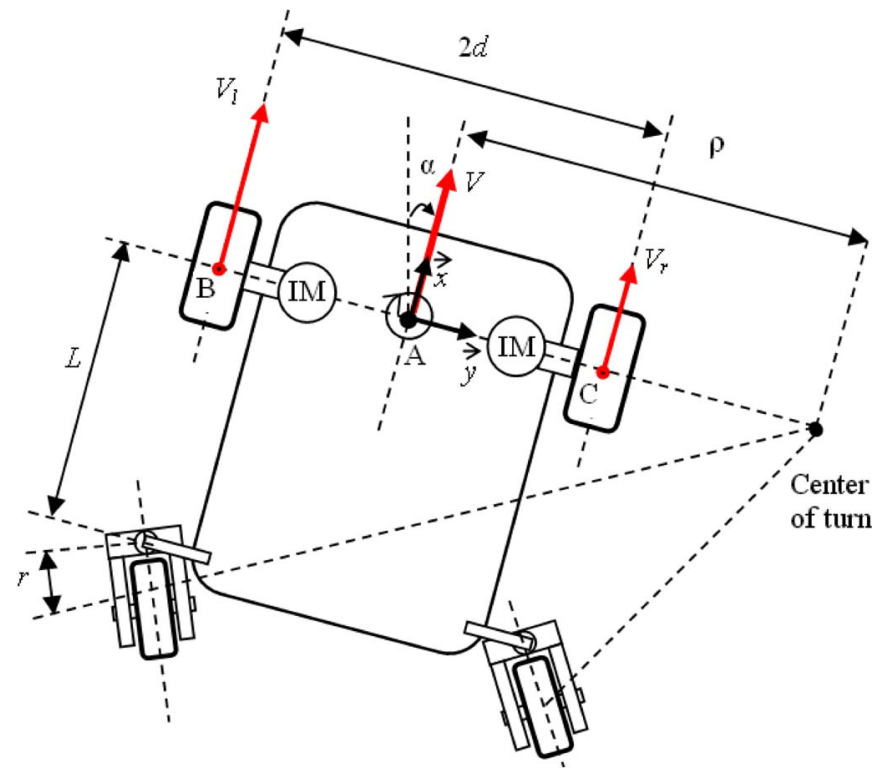

Fig. 5. EV driving trajectory model.

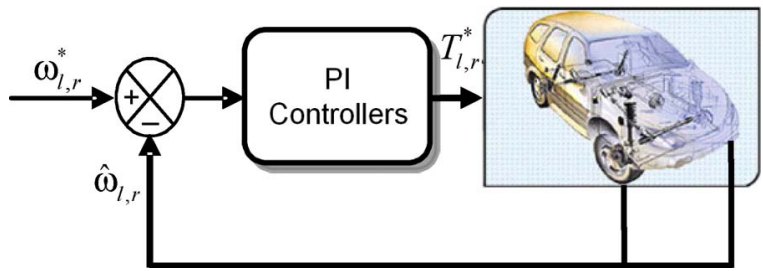

Fig. 6. Reference torque generation block diagram.

The stability analysis (Lyapunov stability theorem) in terms of observation error allows having an asymptotic observer. The speed-adaptive mechanism is then given by

$$
\hat{\omega}_{r}=K_{p e}\left(e_{s \alpha} \hat{\varphi}_{r \beta}-e_{s \beta} \hat{\varphi}_{r \alpha}\right)+K_{i e} \int\left(e_{s \alpha} \hat{\varphi}_{r \beta}-e_{s \beta} \hat{\varphi}_{r \alpha}\right) d t
$$

where $K_{p e}$ and $K_{i e}$ are positive gains, $e_{s \alpha}=i_{s \alpha}-\hat{i}_{s \alpha}$, and $e_{s \beta}=i_{s \beta}-\hat{i}_{s \beta}$.

\section{C. $E D$}

The block diagram of Fig. 2 assumes that the vehicle linear speed $v$ is maintained constant during each maneuver. Therefore, the DTC torque commands are produced by selecting the vehicle desired speed. Each induction motor rotation speed depends on the selected driving regime type [14].

For the straight-line regime, the motor rotation speeds are

$$
\omega_{l}=\omega_{r}=\frac{v}{r} .
$$

For the turning regime (see Fig. 5), the rotation speeds for each motor are different. For example, in the right turning way, these speeds are expressed as

$$
\left\{\begin{array}{l}
\omega_{l}=\frac{2 v}{\left(1+\frac{\rho+2 d}{\rho-2 d}\right) r}=\frac{v}{r}+\Delta \omega \\
\omega_{r}=\frac{2 v}{\left(1+\frac{\rho+d}{\rho-d}\right) r}=\frac{v}{r}-\Delta \omega \\
\Delta \omega=d \frac{v}{\rho r}
\end{array}\right.
$$

where $\Delta \omega$ is imposed when the vehicle crosses a turning way. 


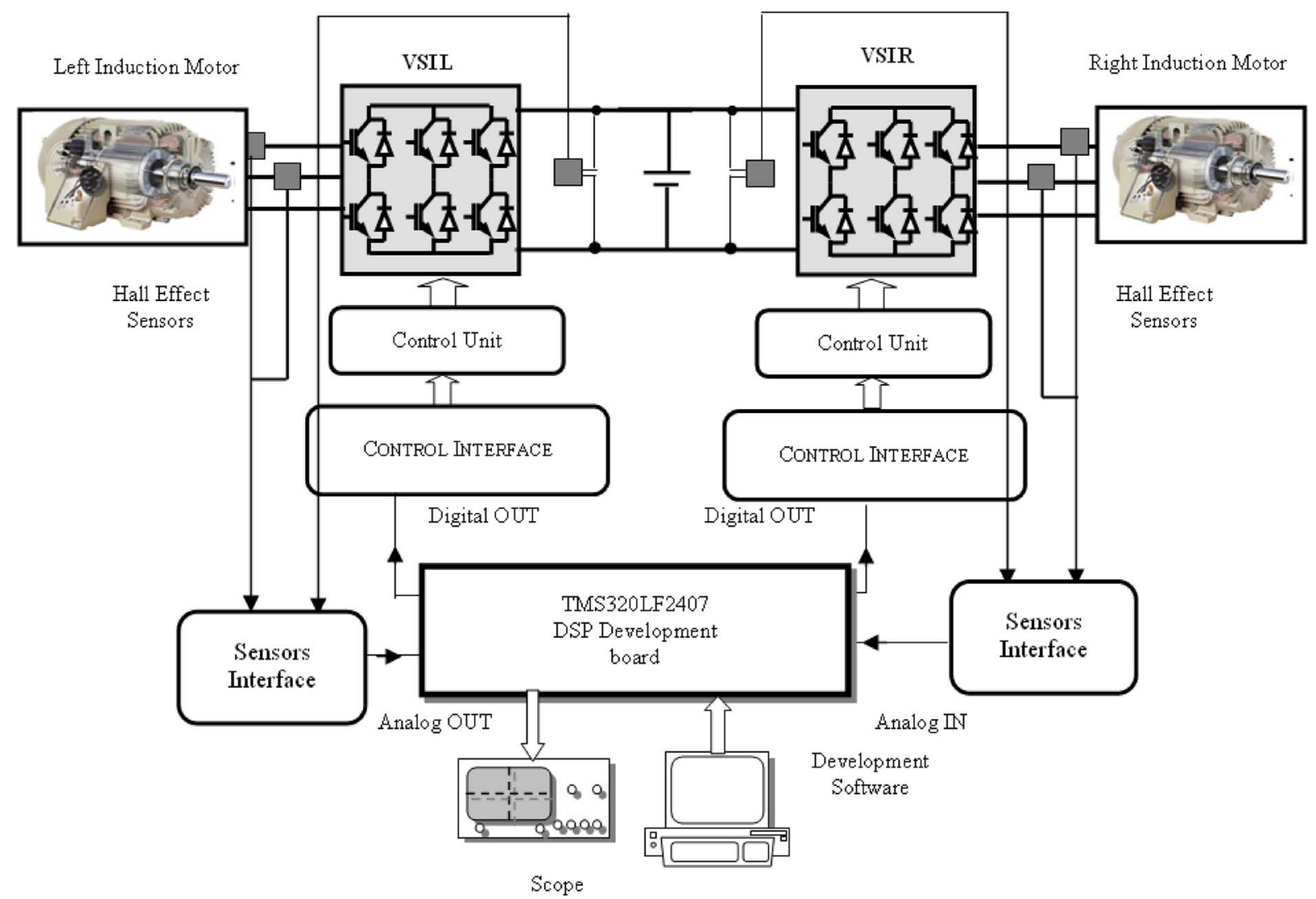

(a)
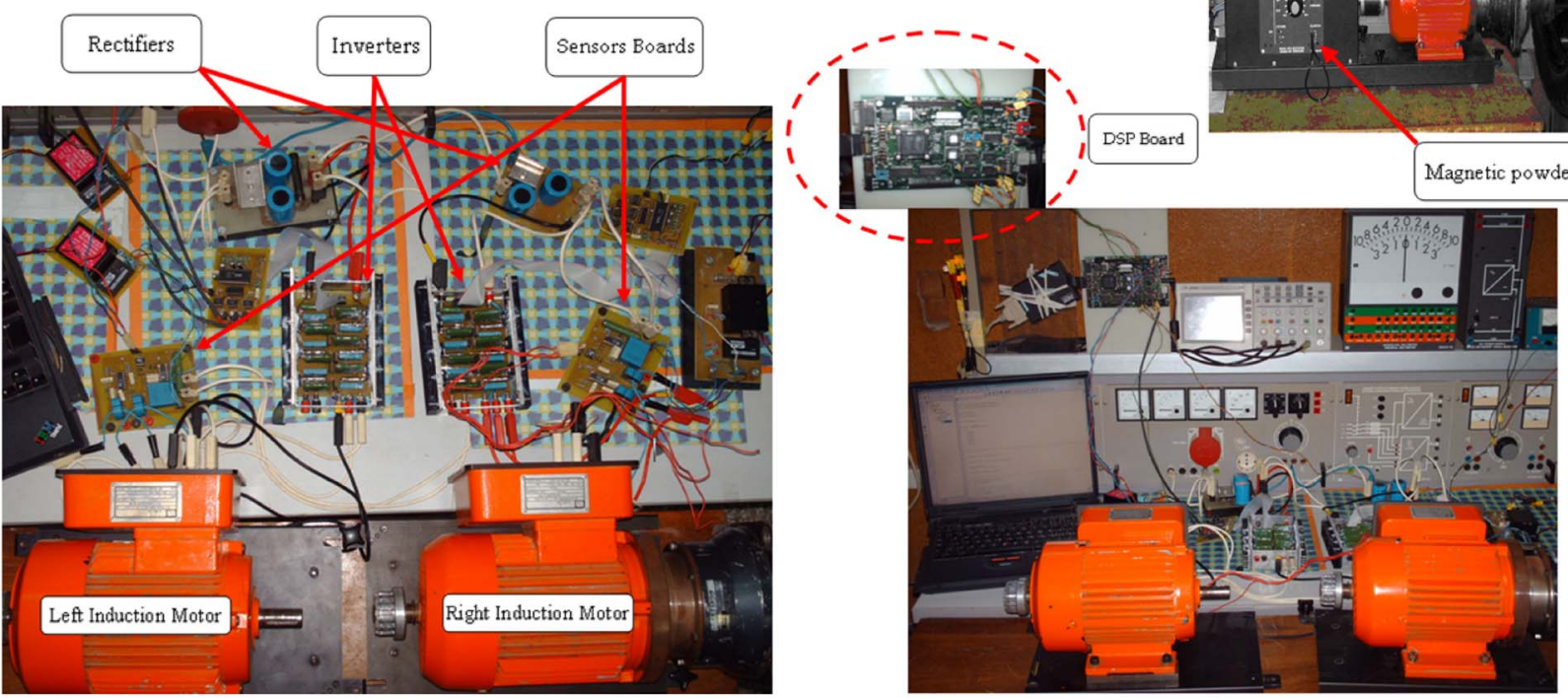

(b)

Fig. 7. Experimental setup. (a) Setup details. (b) Setup pictures.

The vehicle speed is given by

$$
v=r \frac{\omega_{l}+\omega_{r}}{2} .
$$

\section{Reference Torques}

The induction motor references are generated by PI controllers, which maintain the speed constant under any load torque.

It is given by

$$
T_{l, r}^{*}=K_{p}\left(\omega_{l, r}^{*}-\hat{\omega}_{l, r}\right)+K_{i} \int_{t_{0}}^{t}\left(\omega_{l, r}^{*}-\hat{\omega}_{l, r}\right) d t
$$

where $K_{p}$ and $K_{i}$ are PI coefficients.

Fig. 6 shows the block diagram that illustrates the induction motor torque reference generation principal. 
TABLE I

RATED DATA OF THE TESTED INDUCTION MOTORS

$1 \mathrm{~kW}, 50 \mathrm{~Hz}, 400 / 230 \mathrm{~V}, 5 / 2.3 \mathrm{~A}, 24.17 \mathrm{Nm}, 2830 \mathrm{rpm}, p=1$ $R_{S}=4.67 \Omega, R_{r}=10.00 \Omega, L_{S}=0.374 \mathrm{H}, L_{r}=0.374 \mathrm{H}, M=0.364 \mathrm{H}$ $J=0.002 \mathrm{kgm}^{2}, f=0.01$ IS

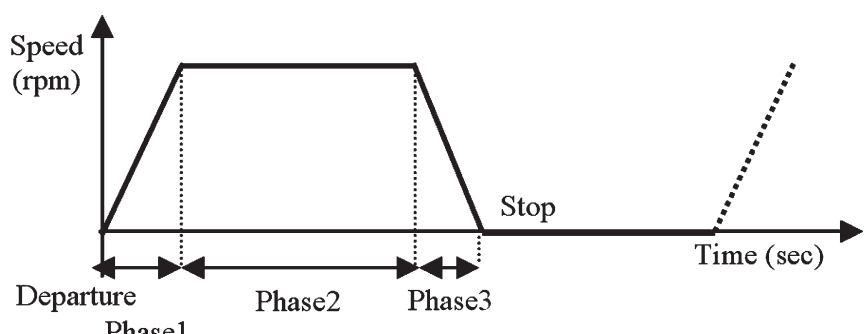

Phase1

Fig. 8. EV speed reference.

\section{EXPERIMENTAL TESTS}

\section{A. Experimental Setup}

The experimental setup details and pictures are shown in Fig. 7. The used cage induction motor rated data are given in Table I. These motors are each supplied by a two-level voltage inverter.

The setup main components are given as follows: a DSP system (single fixed-point TMS320LF2407), an optical encoder attached to the motor shaft only to allow comparison between estimated and measured speeds, and current and voltage sensors. The DSP system is interfaced to a standard power converter. The continuous-time algorithm is discredited with a sampling period of $100 \mu \mathrm{s}$. At each sampling instant, the DSP receives stator current and voltage measurements and then runs the estimation algorithm, the DTC scheme, and the ED.

For the EV driving cycle emulation, a magnetic power brake is used. It allows load torque generation, which is controlled by varying an excitation current. Indeed, the load torque is strictly proportional to the excitation.

\section{B. Vehicle Reference Speed Profile}

Fig. 8 shows the vehicle reference speed profile. This profile consists of Phase 1 (constant acceleration, speed increases linearly), Phase 2 (constant speed), and Phase 3 (constant deceleration, speed decreases linearly).

\section{ED Procedure Tests}

The following two situations have been investigated for the ED tests: 1) the straightway regime, where the two motors operate at the same speed, and 2) the turning-way regime, where each motor operates at different speeds.

\section{Experimental Results}

Figs. 9 and 10 illustrate the proposed ED-based EV dualmotor traction drive performances. Figs. 9(a) and 10(a) illustrate the right and left induction motor speeds under the Fig. 8 driving cycle (with left and right turning ways), re-

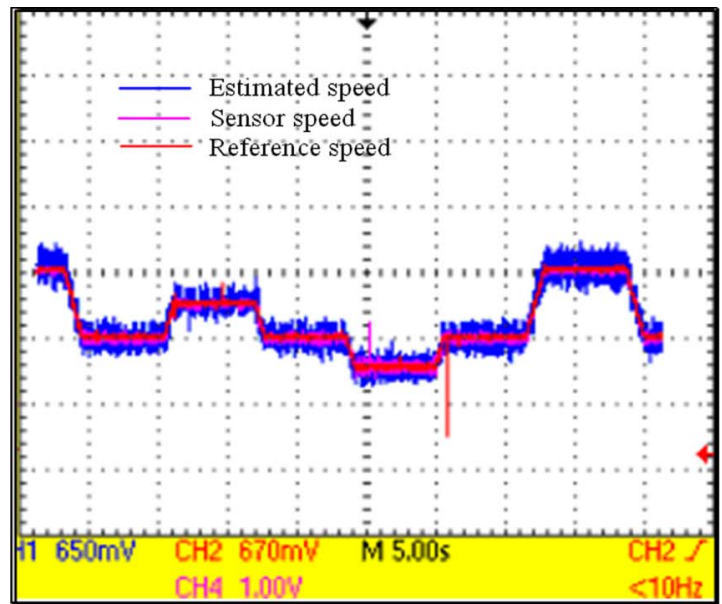

(a)

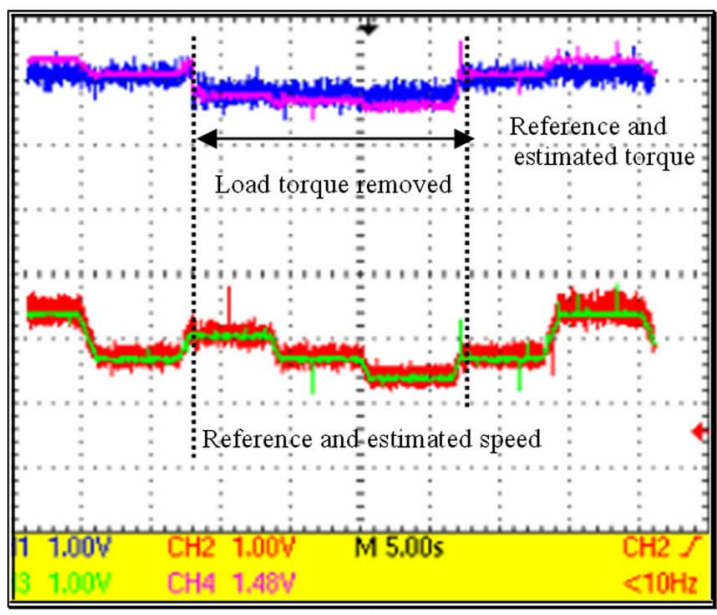

(b)

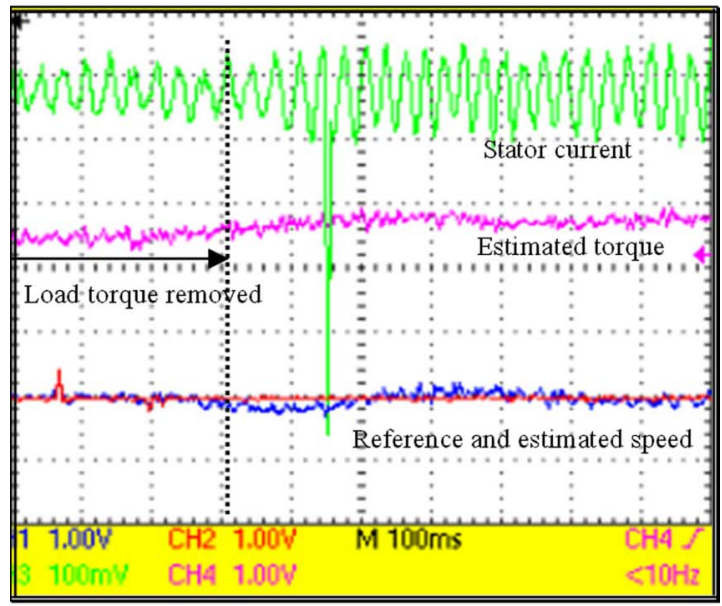

(c)

Fig. 9. Right induction motor dynamic performances. (a) Speed. (b) Estimated torque, speed, and their references. (c) Zoom on the stator current, estimated torque, and estimated and reference speeds.

spectively. In this case, three speeds are shown in Fig. 9(a): (blue) estimated speed, (red) reference speed, and sensor speed, which is shown only for comparison purposes. Figs. 9(b) and 10(b) allow the ED performance evaluation in terms of load torque variations. Finally, the given zoom in Figs. 9(c) and 10(c) clarifies the ED performance in terms of currents under 


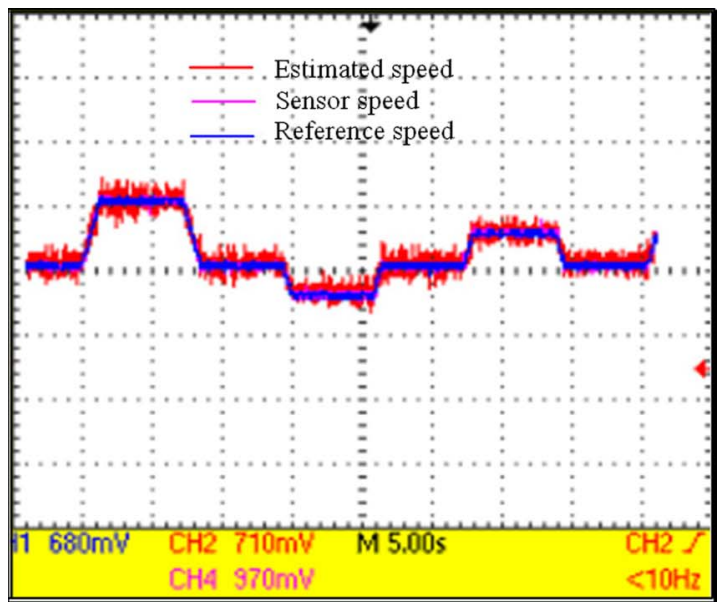

(a)

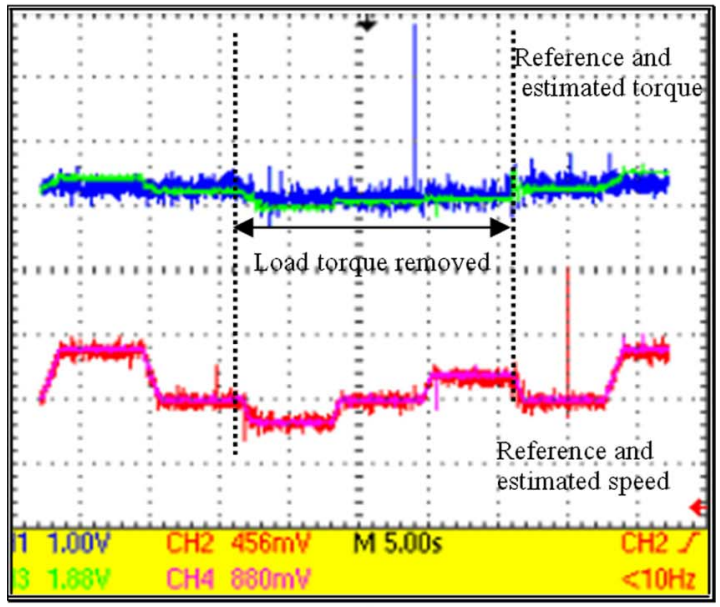

(b)

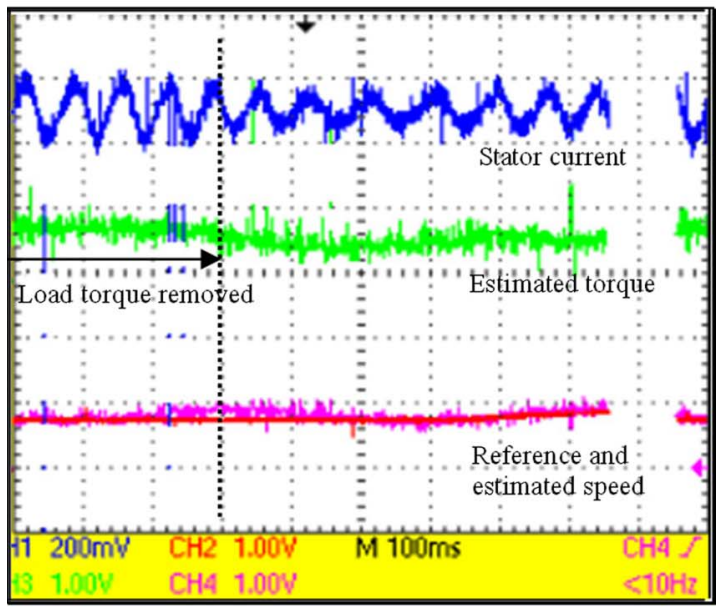

(c)

Fig. 10. Left induction motor dynamic performances. (a) Speed. (b) Estimated torque, speed, and their references. (c) Zoom on the stator current, estimated torque, and estimated and reference speeds.

load torque variations. These obtained results lead to two conclusions.

1) Speed estimations are effective [see Figs. 9(a) and 10(a)].

2) Torque estimations are effective [see Figs. 9(b) and $10(\mathrm{~b})]$.

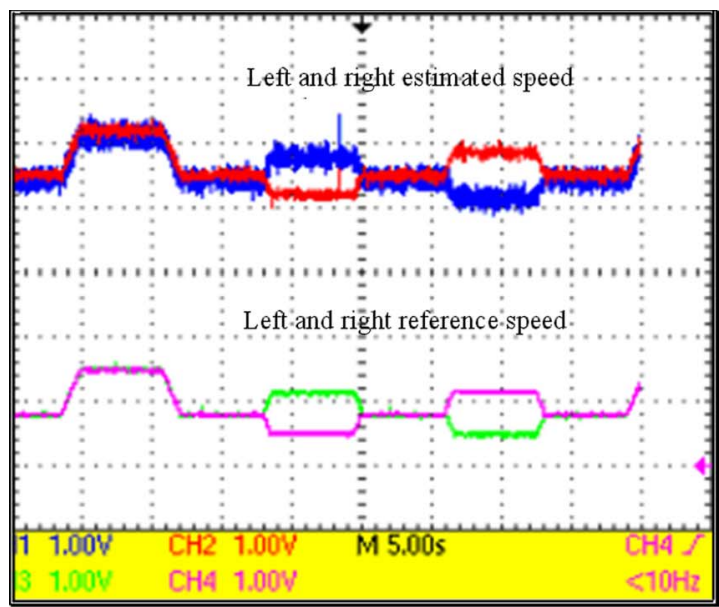

(a)

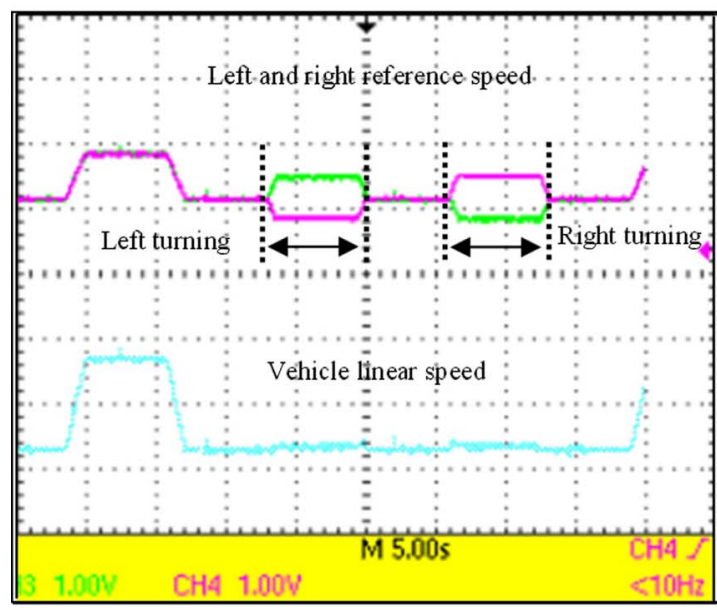

(b)

Fig. 11. EV electronic differential responses. (a) Left and right reference and estimated speeds. (b) Left and right reference speed and vehicle linear speed.

Fig. 11 shows the EV electronic differential responses in terms of right and left induction motor speeds under right and left turning ways [see Fig. 11(a)]. It is obvious that the ED satisfactorily operates according to the applied speed profile [see Fig. 11(b)].

\section{CONCLUSION}

This paper has dealt with an ED-based EV. The ED system will reduce the drive line components, thus improving the overall reliability and efficiency since mechanical differential and gear reduction are not used. In this case, The EV traction drive system uses two separate induction motor drive-based wheels.

The proposed ED has been developed to handle the EV stability while cornering or under slippery road conditions. For that purpose, it uses a DTC and an adaptive-flux-and-speedobserver-based algorithm.

The carried-out specific experimental tests on a DSP TMS320LF2407 have clearly demonstrated the feasibility and the effectiveness of the proposed adaptive ED in terms of robustness and stability without mechanical sensors. However, a comparative study should be carried out to assess the proposed electrical differential efficiency and reliability regarding a traditional mechanical differential. 


\section{REFERENCES}

[1] F. J. Perez-Pinal, I. Cervantes, and A. Emadi, "Stability of an electric differential for traction applications," IEEE Trans. Veh. Technol., vol. 58, no. 7, pp. 3224-3233, Sep. 2009.

[2] A. Haddoun, M. E. H. Benbouzid, and D. Diallo, "Modeling, analysis, and neural network control of an EV electrical differential," IEEE Trans. Ind. Electron., vol. 55, no. 6, pp. 2286-2294, Jun. 2008.

[3] B. Tabbache, A. Kheloui, and N. Hanini, "An electric differential system for a two-wheel mobile plat-form using direct torque control with adaptive flux and speed observers," in Proc. IEEE SPEEDAM, Ischia, Italy, Jun. 2008, pp. 550-556.

[4] N. Mutoh, Y. Hayano, H. Yahagi, and K. Takita, "Electric braking control methods for electric vehicles with independently driven front and rear wheels," IEEE Trans. Ind. Electron., vol. 54, no. 2, pp. 1168-1176, Apr. 2007.

[5] A. Haddoun, F. Khoucha, M. E. H. Benbouzid, and D. Diallo, "SDTC neural network traction control of an electric vehicle without differential gears," in Proc. IEEE VPPC, Arlington, TX, Sep. 2007, pp. 259-266.

[6] M. Zeraoulia, M. E. H. Benbouzid, and D. Diallo, "Electric motor drive selection issues for HEV propulsion systems: A comparative study," IEEE Trans. Veh. Technol., vol. 55, no. 6, pp. 1756-1764, Nov. 2006.

[7] A. Haddoun, M. E. H. Benbouzid, and D. Diallo, "A loss-minimization DTC scheme for EV induction motors," IEEE Trans. Veh. Technol., vol. 56, no. 1, pp. 81-88, Jan. 2007.

[8] F. Khoucha, S. M. Lagoun, K. Marouani, A. Kheloui, and M. E. H. Benbouzid, "Hybrid cascaded H-bridge multilevel-inverter inductionmotor-drive direct torque control for automotive applications," IEEE Trans. Ind. Electron., vol. 57, no. 3, pp. 892-899, Mar. 2010.

[9] I. Vincente, A. Endemano, X. Garin, and M. Brown, "Comparative study of stabilising methods for adaptive speed sensorless full-order observers with stator resistance estimation," IET Control Theory Appl., vol. 4, no. 6, pp. 993-1004, Jun. 2010.

[10] J. Guzinski, H. Abu-Rub, M. Diguet, Z. Krzeminski, and A. Lewicki, "Speed and load torque observer application in high-speed train electric drive," IEEE Trans. Ind. Electron., vol. 57, no. 2, pp. 565-574, Feb. 2010

[11] L. Harnefors and M. Hinkkanen, "Complete stability of reduced-order and full-order observers for sensorless IM drives," IEEE Trans. Ind. Electron., vol. 55, no. 3, pp. 1319-1329, Mar. 2008.

[12] C. C. Chan, "The state of the art of electric, hybrid, and fuel cell vehicles," Proc. IEEE, vol. 95, no. 4, pp. 704-718, Apr. 2007.

[13] A. Bilal, U. Orguner, A. Ersak, and M. Ehsani, "Simple derivative-free nonlinear state observer for sensorless AC drives," IEEE/ASME Trans. Mechatronics, vol. 11, no. 5, pp. 1083-4435, Oct. 2006.

[14] S. Sakai, H. Sado, and Y. Hori, "Motion control in an electric vehicle with four independently driven in-wheel motors," IEEE/ASME Trans. Mechatronics, vol. 4, no. 1, pp. 9-16, Mar. 1999.

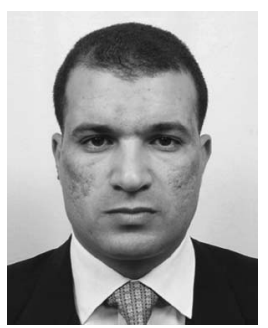

Bekheira Tabbache was born in Chlef, Algeria, in 1979. He received the B.Sc. and M.Sc. degrees in electrical engineering, from the Polytechnic Military Academy, Algiers, Algeria, in 2003 and 2007, respectively. He is currently working toward the Ph.D. degree in electric vehicle fault-tolerant control with the University of Brest, Brest, France.

In 2004, he joined the Department of Electrical Engineering, Polytechnic Military Academy, as a Teaching Assistant.

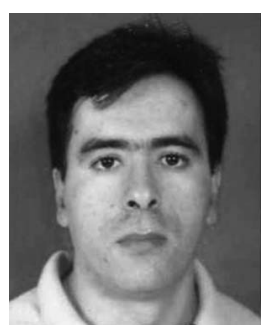

electronics.

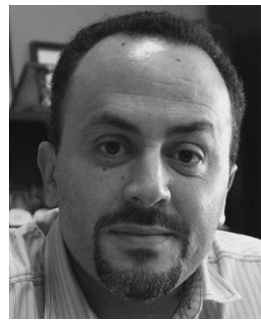

Abdelaziz Kheloui received the M.Sc. degree from the Ecole Nationale d'Ingénieurs et Techniciens of Algeria, Algiers, Algeria, in 1990 and the Ph.D. degree from the National Polytechnic Institute of Lorraine, Nancy, France, in 1994, both in electrical engineering.

Since 1994, he has been with the Department of Electrical Engineering, Polytechnic Military Academy, Algiers, where he has been an Assistant and then an Associate Professor. His current research interests are the control of electrical drives and power Professional Institute of Amiens, University of Picardie "Jules Verne," where he was an Associate Professor of electrical and computer engineering. In September 2004, he joined the University Institute of Technology of Brest, University of Brest, Brest, France, as a Professor of electrical engineering. His research interests include the analysis, design, and control of electric machines; variable-speed drives for traction, propulsion, and renewable-energy applications; and fault diagnosis of electric machines.

Prof. Benbouzid is a Senior Member of the IEEE Power Engineering, Industrial Electronics, Industry Applications, Power Electronics, and Vehicular Technology Societies. He is an Associate Editor for the IEEE TRANSACTIONS ON ENERGy CONVERSION, the IEEE TRANSACTIONS ON INDUSTRIAL ELECTRONICS, the IEEE TRANSACTIONS ON VeHICULAR TECHNOLOGY, and the IEEE/ASME TRANSACTIONS ON MECHATRONICS. 